\title{
A Multi-institutional Study of Peer Instruction in Introductory Computing
}

\author{
Leo Porter ${ }^{1}$, Dennis Bouvier ${ }^{2}$, Quintin Cutts ${ }^{3}$, Scott Grissom ${ }^{4}$, Cynthia Lee ${ }^{5}$, \\ Robert McCartney ${ }^{6}$, Daniel Zingaro ${ }^{7}$, and Beth Simon ${ }^{1}$ \\ ${ }^{1}$ University of California, San Diego \\ ${ }^{2}$ Southern Illinois University Edwardsville \\ ${ }^{3}$ University of Glasgow \\ ${ }^{4}$ Grand Valley State University \\ ${ }^{5}$ Stanford University \\ ${ }^{6}$ University of Connecticut \\ ${ }^{7}$ University of Toronto Mississauga
}

\begin{abstract}
Peer Instruction (PI) is a student-centric pedagogy in which students move from the role of passive listeners to active participants in the classroom. Over the past five years, there have been a number of research articles regarding the value of PI in computer science. The present work adds to this body of knowledge by examining outcomes from seven introductory programming instructors: three novices to PI and four with a range of PI experience. Through common measurements of student perceptions, we provide evidence that introductory computing instructors can successfully implement PI in their classrooms. We find encouraging minimum $(74 \%)$ and average (92\%) levels of success as measured through student valuation of PI for their learning. This work also documents and hypothesizes reasons for comparatively poor survey results in one course, highlighting the importance of the choice of grading policy (participation vs. correctness) for new PI adopters.
\end{abstract}

\section{INTRODUCTION}

Peer Instruction (PI) has gained considerable traction among computer science educators and there have been a number of studies demonstrating its efficacy in a variety of dimensions. Students value PI $[5,8,10]$ and learn more in PI classes compared to traditional lecture classes $[11,13]$. $\mathrm{PI}$ is also associated with low failure rates [6] and increased retention of majors [9].

The vast majority of PI studies in CS take the form of evaluating a single instructor $[5,8,10]$ or implementation at a single institution $[5,6,9]$. As such, one concern is that the reported PI results overrepresent those occasions where PI

Permission to make digital or hard copies of all or part of this work for personal or classroom use is granted without fee provided that copies are not made or distributed for profit or commercial advantage and that copies bear this notice and the full citation on the first page. Copyrights for components of this work owned by others than ACM must be honored. Abstracting with credit is permitted. To copy otherwise, or republish to post on servers or to redistribute to lists, requires prior specific permission and/or a fee. Request permissions from permissions@acm.org.

SIGCSE '16, March 02-05, 2016, Memphis, TN, USA

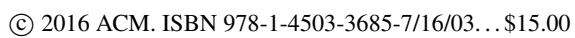

DOI: http://dx.doi.org/10.1145/2839509.2844642 has proven successful. Given the current trend of increased PI adoption, it is important to establish the kinds of outcomes that can be expected across larger datasets and institution types. In addition, it is important to begin studying the ways in which new adopters adopt PI. To what extent is PI adopted wholesale? How are the steps of PI altered to suit the instructor or student demands?

This paper reports on a set of PI adoptions with a broad range of class parameters and types of institutions. Only one other paper has offered such a multi-institution view, but it examined only small classes at private liberal-arts colleges [8]. In the present study, seven instructors and their students, from multiple institutions of different types, were surveyed. The instructors range from new adopters of PI to experienced PI users. The level of success was not uniform across the instructors.

Our key findings are:

- Consistent with previous studies, a supermajority of students in all studied classes liked and would recommend PI.

- Successful PI implementation requires that the instructor's motivations for using PI are clear to students.

- The grading policy attached to in-class PI question responses appears to have an effect on student engagement and satisfaction.

\section{RELATED WORK}

PI is characterized by asking challenging, in-class conceptual questions of students. For each question, students individually respond, discuss the question in small groups, and respond again based on their new understanding [1]. These questions should target common misconceptions and/or core course concepts. To be most effective, PI requires other supporting course changes. For example, many instructors require additional preparation from students before class in order to make best use of limited class time. This preparation can consist of pre-lecture reading and associated quizzes [1, 14] or clicker quizzes at the start of class [14].

Interactive classrooms, including PI classrooms, have shown significant increases in student learning in physics [4]. In 
Table 1: Institution, course, and instructor characteristics. For major, (decl.) and (ant.) denote declared and anticipated, respectively. $\mathrm{N} / \mathrm{A}$ denotes data not available.

\begin{tabular}{|c|c|c|c|c|c|c|c|}
\hline Identifier & $\mathrm{N}-\mathrm{A}$ & N-B & $\mathrm{N}-\mathrm{C}$ & E-D & E-E & E-F & E-G \\
\hline Institution & R1 & $\overline{\mathrm{PUI}}$ & $\overline{\mathrm{PUI}}$ & R1 & R1 & $\mathrm{R} 1$ & $\overline{\mathrm{PUI}}$ \\
\hline Public/Private & Public & Public & Public & Public & Public & Public & Private \\
\hline Language & Java & Java & Java & Python & Alice & Matlab & Java \\
\hline Times Taught this Course & 6 & $10+$ & $10+$ & $10+$ & 2 & 1 & 0 \\
\hline Courses Taught using PI & 0 & 0 & 0 & $0^{\mathrm{a}}$ & 10 & 3 & 1 \\
\hline Percentage of CS majors & $\begin{array}{l}34 \% \text { (decl.) } \\
59 \% \text { (ant.) }\end{array}$ & $50 \%$ & $\begin{array}{c}29 \% \\
\text { (decl.) }\end{array}$ & $\begin{array}{l}70 \% \\
\text { (ant.) }\end{array}$ & $1 \%$ & $6.4 \%$ & $\begin{array}{l}44 \% \\
\text { (ant.) }\end{array}$ \\
\hline Freshman & $3 \%$ & $40 \%$ & $36 \%$ & $>95 \%$ & $34 \%$ & $34 \%$ & $37 \%$ \\
\hline Sophomore & $40 \%$ & $27 \%$ & $42 \%$ & $\mathrm{~N} / \mathrm{A}$ & $45 \%$ & $16 \%$ & $26 \%$ \\
\hline Junior & $37 \%$ & $27 \%$ & $13 \%$ & $\mathrm{~N} / \mathrm{A}$ & $14 \%$ & $33 \%$ & $22 \%$ \\
\hline (D)eveloped or (A)dopted Questions & $\mathrm{D}$ & $\mathrm{D}$ & $\mathrm{D}$ & $\mathrm{D}$ & $\mathrm{D}$ & $\mathrm{D}$ & $\mathrm{A}$ \\
\hline
\end{tabular}

${ }^{a}$ Instructor of course E-D had not taught a class using PI, but had been part of PI research and course development. As such, that instructor is considered experienced in PI.

b 30 minutes each week was spent on a practice code-writing quiz.

CS, a number of studies have reported on the success of PI, including improved student satisfaction [5, 8, 10], student learning [7, 15], final exam grades [11, 13], failure rates [6], and retention of majors [9].

The present work provides additional evidence that, for both new and seasoned adopters of PI, students widely laud the change to the course structure. As noted in earlier research [10], it is not always the case that PI is adopted following all recommended practices. The results of the present work lead us to examine ways in which PI is adopted, and we find suggestive evidence that student satisfaction can be significantly impacted by grading clicker results on correctness rather than participation.

\section{METHOD}

Each of the seven instructors in this study reported the teaching of one introductory programming course. Four of the instructors had experience with PI, either by having taught a course in PI or by having participated significantly in the development of a PI course. The other three instructors were new to PI. We label our courses with two letters: N (novice) or E (experienced) to indicate the instructor's PI experience, and a letter A-G to differentiate each course (assigned, within $\mathrm{N}$ and $\mathrm{E}$ categories, by decreasing years of teaching experience for the instructor). Course and instructor characteristics are provided in Table 1.

A brief description of each course is provided below.

Course N-A: CS 1.5 - Object-Oriented Design and Programming: This course concentrates on the objectoriented paradigm, particularly encapsulation, inheritance, and polymorphism. Programming assignments emphasize graphics and event-driven interaction.
Course N-B: CS1 - Computer Science I: This course is an introduction to programming and computer science whose topics include: simple and structured data types, program control structures, problem analysis, algorithm design, and implementation using a high-level language (Java).

Course N-C CS1-Introduction to Computing I: This Java course covers types/variables, assignment, conditions, loops, classes/objects, files, and arrays.

Course E-D: CS1: This course is an introduction to procedural programming in Python for CS majors covering basic types, expressions, state, control structures, function definition and use, and lists.

Course E-E CS0 - Fluency in Information Technology: This non-majors computing course is required for all psychology majors and as a general education requirement for a subset of university students (those within a specific "college"). The goals of this "general education" course in computing include computational thinking and communicating and collaborating about computational artifacts (in this case Alice programs and Excel sheets).

Course E-F: CS1 - Introduction to Programming in Matlab: This course is an introduction to MATLAB programming for the Cognitive Science department and uses the Media Computation approach [3]. Students study foundational programming constructs such as data manipulation, conditional statements, for-loops, while-loops, and various types of vector and matrix indexing.

Course E-G: CS1 - Computer Science I: This course is a required course for CS and Mathematics majors taught using Media Computation [3]. Concepts include variables, objects, methods, loops, conditionals, and class design. 
Table 2: Student feedback on the value of PI. Percentages reflect student agreement. Agreement values under $80 \%$ are highlighted.

\begin{tabular}{|c|c|c|c|c|c|c|c|}
\hline Question/Identifier & $\mathrm{N}-\mathrm{A}$ & N-B & $\mathrm{N}-\mathrm{C}$ & E-D & E-E & E-F & E-G \\
\hline $\begin{array}{l}\text { Thinking about clicker questions on my own, before discussing } \\
\text { with people around me, helped me learn the course material. }\end{array}$ & $68 \%$ & $86 \%$ & $100 \%$ & $\overline{94 \%}$ & $95 \%$ & $95 \%$ & $100 \%$ \\
\hline Most of the time my group actually discusses the clicker question. & $90 \%$ & $93 \%$ & $100 \%$ & $88 \%$ & $98 \%$ & $97 \%$ & $100 \%$ \\
\hline $\begin{array}{l}\text { The immediate feedback from clickers helped me focus on weak- } \\
\text { nesses in my understanding of the course material. }\end{array}$ & $74 \%$ & $96 \%$ & $100 \%$ & $95 \%$ & $99 \%$ & $91 \%$ & $100 \%$ \\
\hline $\begin{array}{l}\text { Knowing the right answer is the only important part of the clicker } \\
\text { question.* }\end{array}$ & $37 \%$ & $14 \%$ & $15 \%$ & $12 \%$ & $23 \%$ & $17 \%$ & $20 \%$ \\
\hline $\begin{array}{l}\text { Generally, by the time we finished with a question and discussion, } \\
\text { I felt pretty clear about it. }\end{array}$ & $69 \%$ & $90 \%$ & $100 \%$ & $94 \%$ & $97 \%$ & $84 \%$ & $93 \%$ \\
\hline $\begin{array}{l}\text { Clickers helped me pay attention in this course compared to tradi- } \\
\text { tional lectures. }\end{array}$ & $58 \%$ & $93 \%$ & $100 \%$ & $95 \%$ & $90 \%$ & $90 \%$ & $100 \%$ \\
\hline Clickers with discussion is valuable for my learning. & $74 \%$ & $93 \%$ & $100 \%$ & $100 \%$ & $94 \%$ & $91 \%$ & $93 \%$ \\
\hline $\begin{array}{l}\text { I recommend that other instructors use this approach (reading } \\
\text { quizzes, clickers, in-class discussion) in their courses. }\end{array}$ & $71 \%$ & $90 \%$ & $100 \%$ & $98 \%$ & $93 \%$ & $87 \%$ & $100 \%$ \\
\hline
\end{tabular}

One instructor, experienced in teaching PI, is known by all instructors and actively assisted the novice instructors in weekly half-hour Skype meetings during their first PI term. The instructors surveyed their students using a common instrument, which enabled comparison of responses across courses.

\section{RESULTS}

In student self-report surveys, we asked for views on the value of the PI approach in supporting various aspects of the learning experience and views on the instructor's implementation of PI in the classroom.

\subsection{Student Perception of the Value of PI}

Students reported on their perception of the value of PI (see Table 2). For all but one question (denoted with a ${ }^{*}$ ), higher percentages are better. Responses below $80 \%$ positive are highlighted. We note two trends in Table 2.

The first trend is that students overwhelmingly value PI. They report that they pay better attention in class, believe it helps them identify weaknesses earlier, and believe the process helps them learn. As a result, the vast majority of students (91\% per class on average) recommend that more instructors use PI in their courses. In two classes, $100 \%$ of students would recommend that other instructors use PI. These results demonstrate that across a wide range of institutions and instructors, students both value PI and desire that PI be used by more instructors.

The second trend is that the students in Course N-A perceive PI considerably differently than students in other courses. Compared to students in other courses, the students in Course N-A recommend PI less often, felt discussion was less valuable, and generally reported less value from the PI process. Perhaps most striking is the large percentage $(37 \%)$ of students who believe the value of a clicker question is only in having the correct answer. We will revisit this anomalous result in the Discussion.

\subsection{Student Perception of PI Implementation}

Table 3 indicates student satisfaction with how PI was implemented regarding difficulty and timing. To express dissatisfaction, students could respond either "too long"/"too difficult" or "too short"/"too easy."

The majority of classes saw high degrees of satisfaction with the PI implementation. Both Courses N-A and E$\mathrm{F}$ stand out as having lower levels of satisfaction with the implementation, but recall that only Course N-A experienced the overall lower value of PI.

Question Difficulty. In Course N-A, some students (23\%) felt that questions were too difficult. Only two other courses had more than $4 \%$ of students who reported that questions were too difficult: Course E-F with $14 \%$ and Course E-G with $13 \%$.

Question Time Allowed. In general, if students were unsatisfied with the time allowed for the initial vote, then they felt that they had too little time (notably in Courses N-A, N-C, E-D, E-E, and E-G) rather than too much time. Course $\mathrm{N}-\mathrm{A}$ was again an outlier with $21 \%$ of students responding that they had too little time relative to $7 \%$ who felt they had too much time. Although instructors set the questions (and drive the pace), it is critical for students to be given time to think through the questions on their own. Question design (e.g. word choice, clarity, answer options) can seriously impact student time needed to read the question.

Discussion Time Allowed. An interesting trend appears regarding time allowed for peer discussion. Of those students who were not satisfied with the time allowed for peer discussion in the courses of all four experienced instructors, more students felt that too much time was allowed. A possible reason for this is that experienced PI instructors are more comfortable spending time on peer discussion, and may have personal evidence suggesting the value of providing students with more time to talk among themselves. For novice instructors, time circulating in the classroom or silently standing up-front can be initially unnerving, and at the very least is a change in their teaching style. However, results in Course $\mathrm{N}$-A more closely match those of courses taught by experienced instructors in that unsatisfied students felt that too much time was allowed. As can be observed from Figure 1, this may be related to the comparatively fewer students in Course N-A who report always discussing with their peers: if some students are not discussing, then they are waiting for class to move forward. 
Table 3: Student feedback on the implementation of PI. Percentages reflect students responding "OK" or "About right". Values under $80 \%$ are highlighted.

\begin{tabular}{|c|c|c|c|c|c|c|c|}
\hline Question/Identifier & $\mathrm{N}-\mathrm{A}$ & N-B & $\mathrm{N}-\mathrm{C}$ & E-D & E-E & E-F & E-G \\
\hline $\begin{array}{l}\text { From the point of helping me learn, the content of clicker questions } \\
\text { was: (too hard, okay, too easy) }\end{array}$ & $\overline{76 \%}$ & $83 \%$ & $100 \%$ & 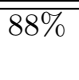 & $\overline{94 \%}$ & $\overline{78 \%}$ & $80 \%$ \\
\hline $\begin{array}{l}\text { In general, the instructor gave us enough time to read and understand } \\
\text { the questions before the first vote: (too short, about right, too long) }\end{array}$ & $72 \%$ & $89 \%$ & $92 \%$ & $81 \%$ & $87 \%$ & $78 \%$ & $87 \%$ \\
\hline $\begin{array}{l}\text { The amount of time generally allowed for peer discussion was: (too } \\
\text { short, about right, too long) }\end{array}$ & $89 \%$ & $87 \%$ & $92 \%$ & $79 \%$ & $86 \%$ & $77 \%$ & $73 \%$ \\
\hline $\begin{array}{l}\text { In general, the time allowed for class-wide discussion (after the group } \\
\text { vote) was: (too short, about right, too long) }\end{array}$ & $70 \%$ & $86 \%$ & $100 \%$ & $64 \%$ & $81 \%$ & $63 \%$ & $93 \%$ \\
\hline
\end{tabular}

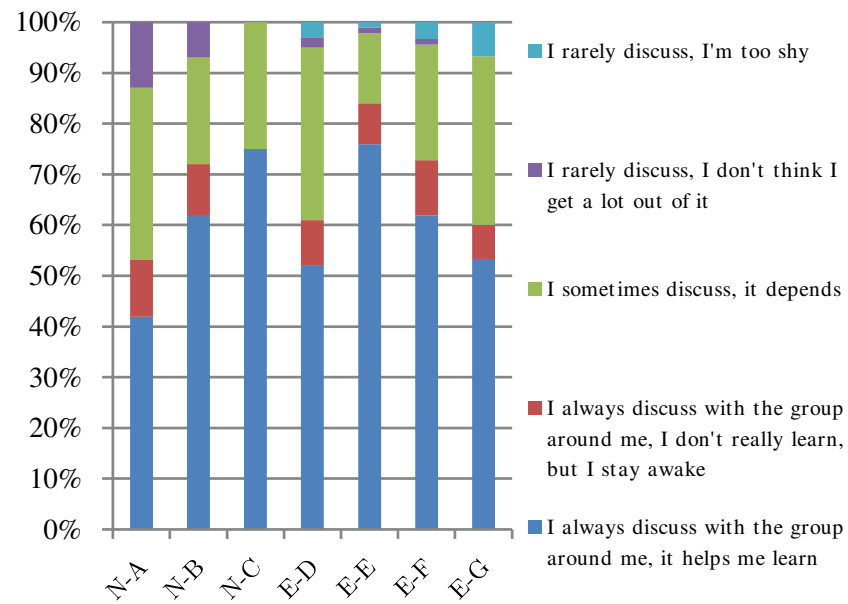

Figure 1: Student responses to the question: Which of the following describes your discussion practices this term?

Class-wide Discussion Time Allowed. Regarding classwide discussions, unsatisfied students felt that they had too much time in Courses N-A, E-D, E-E, and E-F. Course E-F had the most students reporting that too much time was spent on class-wide discussion (26\% too much compared with $11 \%$ too little). This instructor had little experience with the programming language used in the course; it is possible that this caused a mismatch between where students struggled and where the instructor anticipated struggles.

Student Behavior during Discussion. Figure 1 provides the breakdown of student responses regarding their discussion habits. For all but one course, the majority of students reported valuing the discussion with their group as it helped them learn. For all courses, only a small minority of students either did not discuss because they did not value discussion or because they were too shy.

Explanation of the Purpose of PI. Figure 2 provides the breakdown of student responses regarding the explanation from the instructor on why clickers were being used. For all but Instructor N-A, more than $90 \%$ of students thought that the instructor explained the use of clickers well or did so too much. Instructor N-A had a considerably larger percentage of students reporting that they were unclear why they were using clickers. The other anomalous course result was Course E-G, where $20 \%$ of students felt that the instructor explained the use of clickers too much.

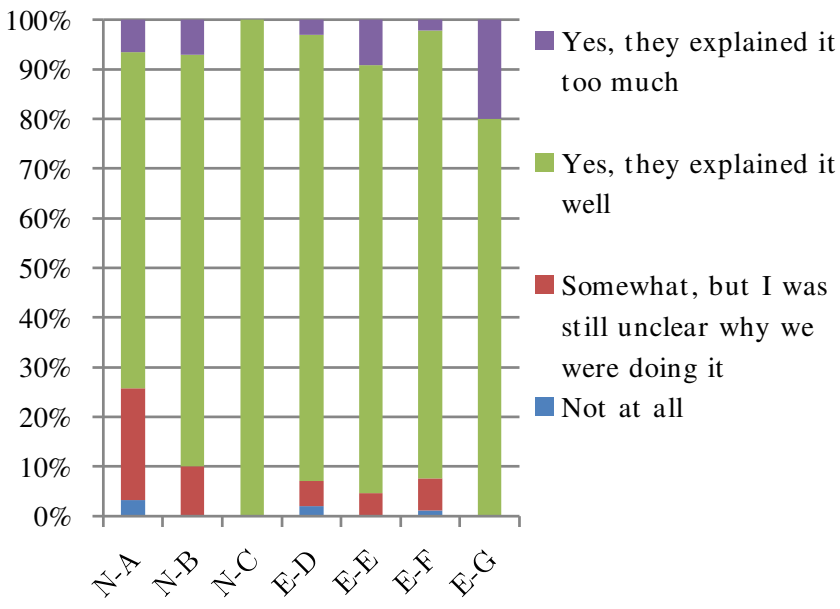

Figure 2: Student responses to the prompt: The professor explained the value of using clickers in this class.

\section{DISCUSSION}

\subsection{Value to Students and Instructors}

Our results suggest that PI can be successfully adopted at a variety of institutions in introductory computing courses. At least $71 \%$ of students (avg. 91\%) would recommend that other instructors use this approach in their courses.

The seven instructors in this work all reported a dramatic change in their usual classroom experience upon implementing PI. These instructors varied in terms of reasons for adoption, amount and type of adoption support, and teaching experience. Instructors had varying comfort levels with the courses and varying support for developing and implementing clicker questions. In fact, some had no more to go on than a notion of allowing students to "test" their knowledge. Some read publications on its use, some reviewed clicker slides prepared and used in computing courses, and some had the opportunity to TA for or repeatedly observe an experienced PI instructor. Independent of these background factors, all instructors report that the next time they teach this class, they will teach it with PI.

This said, one course (N-A) stands out as yielding poor survey results compared to the other courses. We next reflect on why this may be the case.

\subsection{Exploring Course N-A Differences}

Differences between N-A and the other courses can be seen fairly uniformly in both the valuation and implementation 
surveys. Through reflective discussion and our reading of PI reports in other disciplines, we highlight two structural issues for discussion. First, the instructor required correctness for a portion of the PI grade (each question was worth 2 points: 1 for correctness and 1 for participation). Second, a notable $25 \%$ of the class felt that the instructor did not sufficiently explain why clickers were being used. Together, we posit that these two issues contributed to a very different classroom culture regarding PI, as evidenced by the markedly different student survey responses. In sum, students in Course N-A (more than those at other institutions):

1. Felt that clicker questions were too hard

2. Felt that too little time was allotted to read and understand questions

3. Did not always discuss with their peers

4. Did not find value in hearing other students provide explanations in class-wide discussion and,

5. Reported lesser perception of the value of PI for their learning.

\subsubsection{Grading on Correctness}

We suspect that the change from grading on participation to grading on correctness fundamentally changes the atmosphere of the course. Consider the first four points in the above list. This kind of student affect - feelings that questions are too hard and that discussion is not useful make sense if students perceive PI questions as "standard quiz" questions rather than peer discussion questions. The fact that Instructor N-A gave points for correctness, even though he/she also gave points for participation, may have factored into students perceiving questions as a test of something they should already know, rather than tools designed to build their understanding.

There are two other concerns related to grading on correctness rather than participation. The first is that students become concerned about arguing their interpretation of the question, and this can disrupt the learning process. A focus on learning is hampered when an incorrect answer in the learning process itself has grade-based implications. The second, related issue, is that questions cannot be too difficult or will be viewed as unfair. This is problematic when the recommended correctness range for the individual vote on PI questions is 35-70\% [1] and when there is evidence that students benefit considerably more from difficult questions [15]. Instructors who both grade on correctness and recognize the limits that this poses on difficulty may respond in-kind by offering easier questions. This shying away from difficult questions may explain why many students thought that PI was not beneficial for their learning.

We can see evidence of students experiencing Course NA differently than the other courses through open-ended student responses. For example, a student in Course N-A reports:

In this lecture I am more focused on trying to guess the answers to the questions than on internalizing and understanding the course content. In standard lectures I am focused on taking clear and thorough notes and absorbing the material.

-Student in Course $N$-A

A quote from a student in Course E-G may provide more insight into the importance of the grading structure, based on their report of clicker use in a different class:
I have another clicker course, this one is far better. In the other course, every clicker question is graded. It feels too much like the professor just wants to play game show host and puts to [sic] much weight on the correct answers and not the process of getting the answer. This is opposite for this course. I feel like participation should just be graded.

-Student in Course E-G

Given this criticism of grading on correctness, it is essential to examine Course E-E. Like Course N-A, Course E-E had a correctness requirement, but it was differently implemented in a manner that reinforced the role of clicker questions in the learning process rather than the assessment process. In Course E-E, students were graded on participation, but they had to get at least $50 \%$ of all questions (including individual and group responses) in each lecture period correct to get those participation points. This approach was devised based on experience in an earlier offering of the course, which required only participation and where students were noted answering randomly and engaging in unrelated activities in the classroom. The instructor believed that a change in policy was needed based on the fact that the course was a required, non-majors course. Students generally did not start the course with a great deal of enthusiasm, nor much understanding of what value the course held for them. In explaining the "half correct" policy, the instructor was able to reiterate that clicker questions are for helping students engage in developing expert analysis and argumentation skills. The policy reinforced Instructor E-E's primary course learning goal: getting students to learn how computing people see problems.

A student from Course E-E discusses this policy, noting his/her need to prepare, but expressing satisfaction with the awarding of discussion points:

This class was very different from my other classes as it truly made me be on top of my game. I did like the grading structure and how participation points were fair.

-Student in Course E-E

And some students did appear to get the message that their engagement in reasoning about the question, not simply getting points, was the goal.

[I]n [this course], discussion and proof of understanding is a vital part of lecture. With clicker questions, as a student, I was able to engage in thoughtful reasoning.

-Student in Course E-E

\subsubsection{Explaining Pedagogical Change}

It is critically important to explain (repeatedly) to students any deviation from expected classroom norms. Students have both experience with and expectations of college classroom learning. They know what happens in a lecture and have techniques that they expect to use in order to learn and measure their progress toward success. From our collective experience, we can report that students claim that they "have to sit at the front of the class" in order to learn/stay awake, want the instructor to "just explain it," or complain that the lack of lecture "forced me to learn it all myself." PI completely pulls the rug out from under the students by challenging them to re-examine their established, comfortable, and often perceived successful learning habits.

In a popular 2-page "Tips for Successful Clicker Use" summary, Douglas Duncan (Univ. of Colorado, Astronomy) lists as his second tip: "You MUST MUST MUST explain to students why you are using clickers. If you don't, they often 
assume your goal is to track them like Big Brother, and force them to come to class. Students highly resent this." (emphasis original)[12]. Perhaps more tellingly, the first item on his list of Practices that Lead to Failure is "1. Fail to explain why you are using clickers." [2]

In Course N-A, $74 \%$ of students report that their instructor explained to the class why he/she was using clickers. However, the remaining $26 \%$ of students who felt that clickers were not explained adequately (or at all) was the highest percentage among the courses. This emphasizes the importance of explaining the value of PI not just once and in not just one way. Moreover, for Course N-A, it is likely that students were especially sensitive to this issue as most students had previously taken an introductory course where the instructor used clickers to take attendance. The presence of these kinds of non-pedagogical uses of clickers only heightens the need to explain the pedagogical goals of PI.

\subsubsection{Other Factors}

Note that, in addition to the two structural issues we have highlighted, Course N-A also differs from other courses in other ways. The course is a CS 1.5 course (not a CS1 course), many of the students used clickers in the past, and the proportion of freshmen is lower. There is little precedence for these differences contributing to the outlying survey results for this course, however. The earliest experience reports of PI in CS report on successful adoption in CS1.5 courses [10], and we know of no evidence suggesting that any novelty of clickers wears off after a single course.

\section{CONCLUSION}

In this multi-institutional study of student satisfaction in Peer Instruction (PI) courses, we find further evidence of PI being highly valued by students. We also find that one course yielded lower student satisfaction than the other courses. We have argued that this lower satisfaction may have stemmed from two adoption decisions: grading on correctness, and not convincingly arguing to students why clickers and PI are being used. We offer two conclusions here. First, new adopters of PI can expect levels of success similar to those reported by others with considerable PI teaching and development experience. Second, it is important to evaluate adoption decisions. A pedagogy so widely-applicable as PI will inevitably engender debate over the particulars of dayto-day implementation and interaction with students. We encourage all PI instructors to reflect on and make explicit the reasons undergirding their PI-based decisions so as to maximize the value of PI for students.

\section{ACKNOWLEDGEMENTS}

Thank you to the reviewers for their helpful suggestions. This work was supported in part by NSF grant 1140731 .

\section{REFERENCES}

[1] C. H. Crouch and E. Mazur. Peer instruction: Ten years of experience and results. American Journal of Physics, 69, 2001.
[2] D. Duncan. Tips for Successful "Clicker" Use, 2008. Accessed 8/24/15.

[3] M. Guzdial. A media computation course for non-majors. ACM SIGCSE Bulletin, 35(3):104-108, 2003.

[4] R. R. Hake. Interactive-engagement vs. traditional methods: A six-thousand-student survey of mechanics test data for introductory physics courses. American Journal of Physics, 66(1), 1998.

[5] C. B. Lee, S. Garcia, and L. Porter. Can peer instruction be effective in upper-division computer science courses? Transactions on Computing Education, 13(3):12:1-12:22, Aug. 2013.

[6] L. Porter, C. Bailey Lee, and B. Simon. Halving fail rates using peer instruction: A study of four computer science courses. In Proceeding of the 44th ACM Technical Symposium on Computer Science Education, 2013.

[7] L. Porter, C. Bailey-Lee, B. Simon, and D. Zingaro. Peer instruction: Do students really learn from peer discussion in computing? In 7th Annual International Computing Education Research Workshop, 2011.

[8] L. Porter, S. Garcia, J. Glick, A. Matusiewicz, and C. Taylor. Peer instruction in computer science at small liberal arts colleges. In Proceedings of the 18th ACM Conference on Innovation and Technology in Computer Science Education, 2013.

[9] L. Porter and B. Simon. Retaining nearly one-third more majors with a trio of instructional best practices in cs1. In Proceeding of the 44th ACM Technical Symposium on Computer Science Education, 2013.

[10] B. Simon, M. Kohanfars, J. Lee, K. Tamayo, and Q. Cutts. Experience report: Peer instruction in introductory computing. In Proceedings of the $41 \mathrm{st}$ SIGCSE technical symposium on computer science education, 2010.

[11] B. Simon, J. Parris, and J. Spacco. How we teach impacts student learning: Peer instruction vs. lecture in cs0. In Proceeding of the 44th ACM Technical Symposium on Computer Science Education, 2013.

[12] C. Wieman. Clicker Resource Guide. CWSEI - Carl Wieman Science Education Initiative at the University of British Columbia, 2015. Accessed 8/24/15.

[13] D. Zingaro. Peer instruction contributes to self-efficacy in cs1. In Proceedings of the 45th ACM technical symposium on Computer Science Education, pages 373-378, 2014.

[14] D. Zingaro, C. Bailey Lee, and L. Porter. Peer instruction in computing: The role of reading quizzes. In Proceeding of the 44th ACM Technical Symposium on Computer Science Education, 2013.

[15] D. Zingaro and L. Porter. Peer instruction in computing: The value of instructor intervention. Computers \&f Education, 71:87-96, 2014. 